\title{
Identification of a Simple Chemical Structure Associated with Protective Human Antibodies against Multiple Pneumococcal Serogroups ${ }^{\nabla}$
}

\author{
Saeyoung Park, ${ }^{1}$ Archana R. Parameswar, ${ }^{2}$ Alexei V. Demchenko, ${ }^{2}$ and Moon H. Nahm ${ }^{1 *}$ \\ University of Alabama at Birmingham, Birmingham, Alabama 35294, ${ }^{1}$ and University of Missouri-St. Louis, \\ St. Louis, Missouri $63121^{2}$
}

Received 19 March 2009/Returned for modification 30 April 2009/Accepted 11 May 2009

\begin{abstract}
Streptococcus pneumoniae, a major human pathogen, expresses at least 91 serologically distinct carbohydrate capsules. Since pneumococcal vaccines are designed to elicit antibodies against many different capsular polysaccharides (PSs), it is important to identify the epitopes involved in eliciting anti-capsular PS antibodies. We investigated the epitopes recognized by Dob1, which is a hybridoma-secreting human immunoglobulin G2 antibody to the PS of serotype 6B (Y. Sun et al., Infect. Immun. 67:1172-1179, 1999). We found that Dob1 bound synthetic capsular carbohydrates Gal $(1 \rightarrow 3) \alpha-D-G I c p(1 \rightarrow 3) \alpha$-L-Rhap $(1 \rightarrow 3)$ Rib-ol and $\alpha$-D$\operatorname{GIc} p(1 \rightarrow 3) \alpha$-L-Rhap $(1 \rightarrow 3)$ Rib-ol but did not bind $\alpha$-L-Rhap $(1 \rightarrow 3)$ Rib-ol. The critical epitope $\alpha$-D$\operatorname{Glcp}(1 \rightarrow 3) \alpha-L-R h a p$ is found in the capsular PSs of serotypes 6A, 6B, 6C, and 19A but not in the 19F PS. Consistent with this observation, Dob1 bound to the PSs of serotypes 6A, 6B, 6C, and 19A but did not bind the 19F PS and 23 additional unrelated pneumococcal capsular PSs. Also, Dob1 could opsonize pneumococci expressing serotypes $6 \mathrm{~A}, 6 \mathrm{~B}, 6 \mathrm{C}$, and $19 \mathrm{~A}$ but did not opsonize $19 \mathrm{~F}$ pneumococci. In addition, ca. $7 \%$ of immune sera (12 of 175 sera) had significant amounts of Dob1-like antibodies, i.e., reacted with 6B and 19A PSs, but not with 19F PS. Humans can produce antibodies to the Dob1 epitope and the antibodies to that epitope cross-react with the four serotypes $6 \mathrm{~A}, 6 \mathrm{~B}, 6 \mathrm{C}$, and 19A that belong to different serogroups. This epitope may be useful for producing a totally synthetic, simple chemical structure that is capable of generating protective antibodies to multiple pneumococcal serogroups.
\end{abstract}

Streptococcus pneumoniae is a major human pathogen that is responsible for a large percentage of the cases of pneumonia, bacteremia, meningitis, and otitis media in young children and old adults (5). Most pathogenic pneumococci express a carbohydrate capsule, which is recognized as their most important virulence factor. Because of their importance, pneumococcal capsules have been the subject of extensive chemical and serological studies. These studies have found that pneumococci, as a species, produce at least 91 different pneumococcal serotypes (22). In some cases, capsular polysaccharides (PSs) from two serotypes are sufficiently similar in structure that antibodies to one capsule type can cross-react with the similar capsule type (14). For instance, serotype 6B PS, which differs from 6A PS in only one chemical linkage (Table 1), can elicit antibodies that cross-react with 6A PS (31). Such serologically related serotypes are grouped together to form a single serogroup (8, 15). Also, for such cross-reacting antibodies to be cross-protective, they should opsonize pneumococci expressing crossreactive serotypes as well.

Since antibodies to the carbohydrate capsules of pneumococci can protect the host, currently available pneumococcal vaccines are designed to elicit antibodies to the capsule. Old adults are routinely immunized with the 23 -valent pneumococcal PS vaccine (PPV23) (25), and young children are immu-

\footnotetext{
* Corresponding author. Mailing address: University of Alabama at Birmingham, BBRB 614, 1530 Third Avenue South, Birmingham, AL 35294-2170. Phone: (205) 934-0163. Fax: (205) 975-2149. E-mail: nahm @uab.edu.

${ }^{\nabla}$ Published ahead of print on 18 May 2009.
}

nized with a PS-protein conjugate vaccine. A widely used conjugate vaccine is the 7-valent pneumococcal conjugate vaccine (PCV7). Although the "conjugate vaccine" has been found to be highly effective, chemical conjugation is technically difficult. In addition, the conjugate vaccines are expensive to produce and usually contain only a limited number of serotypes (e.g., 7 to 13 serotypes) $(24,33)$. To allow more serotypes to be included in conjugate vaccines, extensive efforts are under way to increase the efficiency of conjugating PS to proteins.

Another approach to improving conjugate vaccines is to identify simple chemical structures that can elicit antibodies to the capsule $(11,13,27)$. Various groups of researchers have chemically synthesized parts of capsular PS and tested those "parts" for their ability to elicit antibodies in animals (27). However, animal studies provide unreliable guidance since the immunogenicity of the chemical constructs is species dependent. This limitation may be overcome if various chemical constructs can first be tested for their ability to bind to human immune sera. When we explored this idea using the human monoclonal antibody Dob1, which was previously reported to be specific for pneumococcal serogroup 6 PSs (30), we discovered a novel epitope shared between 19A PS and serogroup 6 PSs.

\section{MATERIALS AND METHODS}

Antipneumococcal antisera and monoclonal antibody Dob1. Old adult volunteers were immunized with the 23-valent PS vaccine (PNU-Immune 23 [WyethLederle Lab, Pearl River, NY]; Pneumovax [Merck, Whitehouse Station, NJ]) or with an experimental 9-valent pneumococcal conjugate vaccine (PCV9; WyethLederle Lab) (21). Serum samples were collected from the volunteers 1 month 
TABLE 1. Structure of pneumococcal PSs and synthetic carbohydrates used in this study

\begin{tabular}{|c|c|c|}
\hline Category & Serotype & Structure \\
\hline Pneumococcal PSs & $\begin{array}{l}6 \mathrm{~A} \\
6 \mathrm{~B} \\
6 \mathrm{C} \\
14\end{array}$ & 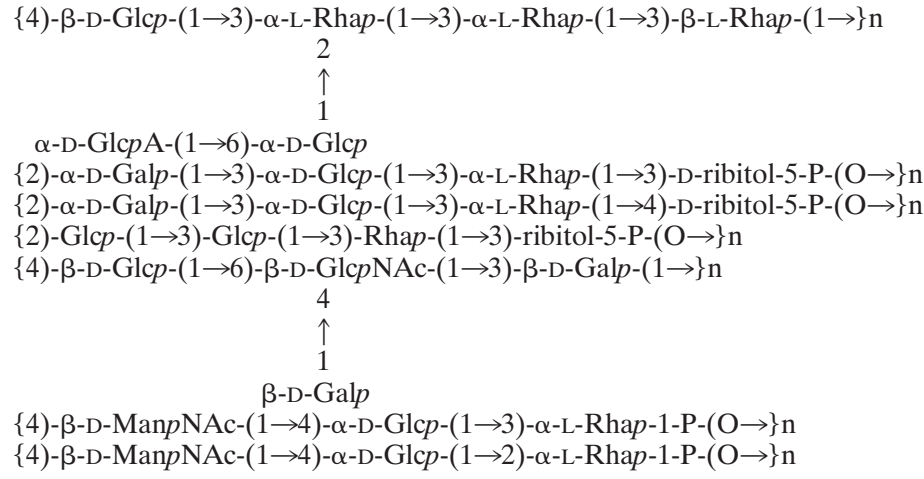 \\
\hline Synthetic carbohydrates & $\begin{array}{l}\text { (6A Di)-BSA } \\
\text { (6A Tri)-BSA } \\
\text { (6A Tetra)-BSA } \\
\text { (6B Di)-BSA } \\
\text { (6B Tri)-BSA } \\
\text { (6B Tetra)-BSA }\end{array}$ & 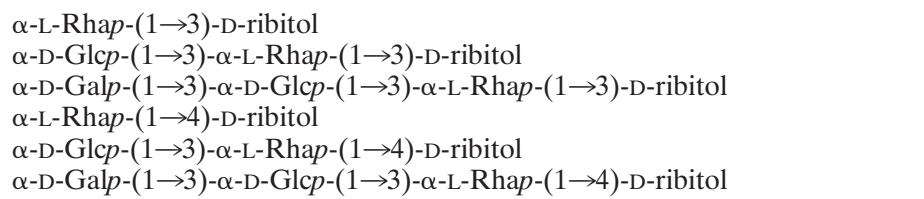 \\
\hline
\end{tabular}

after vaccination. Detailed descriptions of vaccinees and the vaccination protocols were previously reported (21).

As previously described (30), Dob1 is a human monoclonal antibody obtained with peripheral blood cells from a person who was immunized with PPV23. The peripheral blood cells were hybridized with a fusion partner (K6H6/B5), and resulting hybridomas were selected for binding to 6B PS. The precursor B cells for Dob1 may have been stimulated with either 19A or 6B PS since both are in PPV23.

Using ELISA to determine Dob1's ability to bind to pneumococcal capsular PSs or synthetic carbohydrates. Enzyme-linked immunosorbent assay (ELISA) plates were coated with capsular PS (American Type Culture Collection, Rockville, $\mathrm{MD}$ ) or with bovine serum albumin (BSA)-conjugated synthetic carbohydrates that were produced as previously described $(19,20)$ and are summarized in Table 1. To coat the plates with PS, the plates were incubated with capsular PS $(2 \mu \mathrm{g} / \mathrm{ml})$ in phosphate-buffered saline (PBS) with $0.02 \% \mathrm{NaN}_{3}$ for $5 \mathrm{~h}$ at $37^{\circ} \mathrm{C}$. To coat the plates with synthetic carbohydrates, the plates were incubated with BSA-conjugated synthetic carbohydrates [(6B Tri)-BSA, $2 \mu \mathrm{g} / \mathrm{ml}]$ in $0.1 \mathrm{M}$ $\mathrm{Na}_{2} \mathrm{CO}_{3}$ buffer ( $\mathrm{pH} 9.6$ ) overnight at $4^{\circ} \mathrm{C}$. The plates were then washed with PBS containing $0.05 \%$ Tween 20 and loaded with various dilutions of culture supernatant of Dob1 hybridoma (30). After $2 \mathrm{~h}$ of incubation at room temperature, the plates were washed and loaded with alkaline phosphatase (AP)-conjugated goat antibody specific for human immunoglobulin $\mathrm{G}(\mathrm{IgG})$ in $\mathrm{PBS}$ with $0.02 \% \mathrm{NaN}_{3}$. After $2 \mathrm{~h}$ of incubation at room temperature, the plates were loaded with $p$-nitrophenyl phosphate substrate in diethanolamine buffer. After 1 to $2 \mathrm{~h}$ of incubation at room temperature, the reactions were stopped with $3 \mathrm{~N} \mathrm{NaOH}$, and the optical densities at 405 and $690 \mathrm{~nm}$ were measured by using an ELISA plate reader.

Inhibition ELISA. ELISA plates were coated with 6B capsular PS as described above. Those plates were then loaded with antibodies and pneumococcal capsular PS of one serotype. The pneumococcal capsular PS was from serotype 2, $6 \mathrm{~A}, 6 \mathrm{~B}, 6 \mathrm{C}, 19 \mathrm{~A}$, or $19 \mathrm{~F}$, and the antibodies were Dob1 $(2 \mu \mathrm{g} / \mathrm{ml})$ or serum samples (diluted 1:200) from persons who were vaccinated with PPV23 or PCV9. Serum samples were preabsorbed with $5 \mu \mathrm{g}$ of C-PS and $10 \mu \mathrm{g}$ of serotype $22 \mathrm{~F}$ $\mathrm{PS} / \mathrm{ml}$. After $1 \mathrm{~h}$ of incubation at $37^{\circ} \mathrm{C}$, the plates were washed with PBS-T and then loaded with AP-conjugated goat antibody specific for human IgG in PBS-T with $0.02 \% \mathrm{NaN}_{3}$. After $2 \mathrm{~h}$ of incubation at room temperature, the plates were washed. The amount of AP bound to the plates was then measured as described above. The percent inhibition was calculated as follows: percent inhibition $=\{1-$ (the absorbance of serum with inhibitor/the absorbance of serum without inhibitor) $\} \times 100 \%$.

Opsonization assay. A previously described opsonization assay procedure was used (4). Target pneumococci were grown in Todd-Hewitt broth with $0.5 \%$ yeast extract, divided into aliquots, and kept frozen at $-70^{\circ} \mathrm{C}$ until used. HL-60 cells were differentiated into granulocytic cells by culturing them in RPMI 1640 with
$10 \%$ fetal calf serum and $0.8 \%$ dimethyl formamide for 5 days. After the differentiation, the HL-60 cells were diluted to $10^{7}$ cells $/ \mathrm{ml}$ in Hanks buffer supplemented with $0.1 \%$ gelatin and $10 \%$ fetal calf serum. Dob1 was also diluted in the same buffer. Then, $10 \mu \mathrm{l}$ of solution containing 1,000 CFU of pneumococci and $20 \mu \mathrm{l}$ of Dob1 was placed in a well of a 96-well microtiter plate. After $30 \mathrm{~min}$ of incubation at room temperature, $40 \mu \mathrm{l}$ of HL-60 suspension $\left(4 \times 10^{5}\right.$ per well $)$ and $10 \mu \mathrm{l}$ of baby rabbit complement (Pelfreez, Browndeer, WI) were added to the well. The mixture was then incubated for $45 \mathrm{~min}$ at $37^{\circ} \mathrm{C}$ with shaking. After $45 \mathrm{~min}$ of incubation, the plates were placed on ice for 10 to $15 \mathrm{~min}$. An aliquot of the final reaction mixture was then spotted onto Todd-Hewitt broth- $0.5 \%$ yeast extract agar plates. After application of an overlay agar containing one of the four antibiotics (streptomycin, optochin, spectinomycin, and trimethoprim) to each Todd-Hewitt broth- $0.5 \%$ yeast extract agar plate and overnight incubation at $37^{\circ} \mathrm{C}$, the number of bacterial colonies in the agar plates were enumerated. Opsonization titers were defined as the serum dilution that kills $50 \%$ of bacteria. Typically, samples were tested in duplicates of eight dilutions.

IEF. Analytical isoelectric focusing (IEF) was performed as described previously $(10,28)$ with modifications. Polyacrylamide gels $(75$ by 80 by $1.5 \mathrm{~mm})$ were prepared by polymerizing $4.8 \%$ acrylamide-bisacrylamide (29:1) solution (BioRad Laboratories) containing 2.4\% ampholine (pH 3.0 to 10.0; Fluka, Switzerland), $0.04 \%$ ammonium persulfate, and $0.17 \%$ TEMED $\left(N, N, N^{\prime}, N^{\prime}\right.$-tetramethylethylenediamine) in a minigel apparatus (Bio-Rad Laboratories). Next, $2 \mu \mathrm{l}$ of Dob1 culture supernatant was loaded on the gel in $2 \times$ sample buffer $(50 \%$ glycerol, 2.4\% ampholine [pH 3.0 to 10.0]) and focused for $1 \mathrm{~h}$ at $100 \mathrm{~V}, 1 \mathrm{~h}$ at $250 \mathrm{~V}$, and $20 \mathrm{~min}$ at $500 \mathrm{~V}$. The cathode buffer contained $20 \mathrm{mM}$ lysine (free base) and $20 \mathrm{mM}$ arginine (free base), and the anode buffer was $7 \%$ phosphoric acid.

After focusing, the antibodies were transferred to a PS-coated polyvinylidene fluoride (PVDF) membrane by blotting for $30 \mathrm{~min}$ at room temperature. The PVDF membrane was coated with PS by soaking it in pneumococcal PS of serotype $6 \mathrm{~B}, 19 \mathrm{~A}$, or 19F in PBS overnight at room temperature and by blocking with 5\% nonfat dried milk in PBS for $2 \mathrm{~h}$. After the blotting, the membrane was incubated with horseradish peroxidase-conjugated goat antibody specific for human IgG in $2 \%$ nonfat dried milk in PBS overnight at $4^{\circ} \mathrm{C}$. After being washed in PBS-T three times, the membrane was incubated with horseradish peroxidase substrates and enhanced chemiluminescence substrate (Pierce, Rockford, IL) and, finally, was exposed to X-ray film (Biomax MR; Eastman Kodak, Rochester, NY).

\section{RESULTS}

Dob1 recognizes $\alpha$-D-GIcp $(1 \rightarrow 3) \alpha-L-R h a p$ as its epitope. To determine the epitope recognized by Dob1, we investigated its 


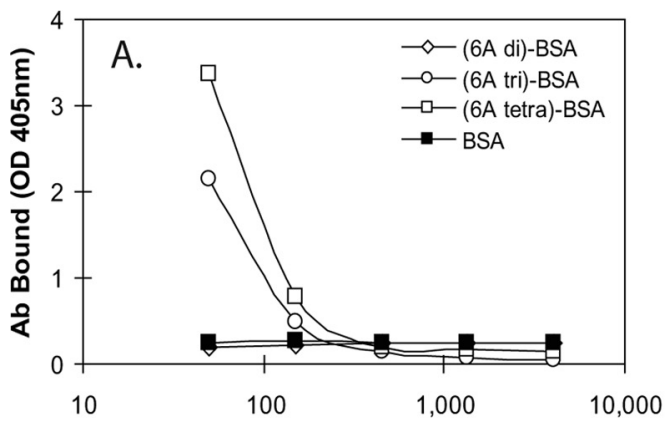

Dob1 Fold Dilutions

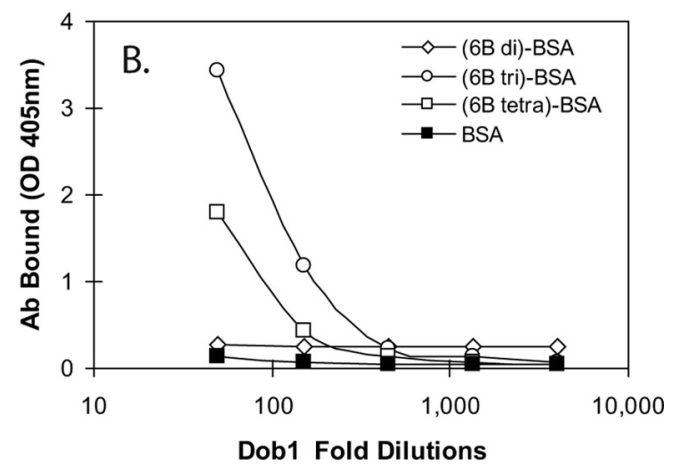

FIG. 1. Binding of Dob1 monoclonal antibody to synthetic carbohydrates conjugated to BSA. The synthetic carbohydrates mimic either 6A PS (A) or 6B PS (B). The structure of each synthetic carbohydrate is shown in Table 1. The amounts of antibody bound to ELISA plates are shown as the optical density at $405 \mathrm{~nm}$.

binding to synthetic carbohydrates that mimic various parts of the 6A and 6B PS repeating unit (Table 1) $(19,20)$. As shown in Fig. 1, even after a 1:200 dilution, a significant amount of Dob1 hybridoma supernatant bound to (6A Tri)-BSA, (6A Tetra)-BSA, (6B Tri)-BSA, and (6B Tetra)-BSA, all of which contain $\alpha$-D-Glc $p(1 \rightarrow 3) \alpha$-L-Rhap in their structure. In contrast, even at a 1:40 dilution, Dob1 did not bind to (6A Di)BSA or (6B Di)-BSA, which do not contain $\alpha$-D-Glcp $(1 \rightarrow 3) \alpha$ L-Rhap. Thus, $\alpha$-D-Glc $p(1 \rightarrow 3) \alpha$-L-Rhap is likely the epitope for Dob1.

Dob1 binds to PSs from different serogroups. A comparison of the chemical structures of the pneumococcal PSs of the various serotypes showed that the $\alpha$-D-Glcp $(1 \rightarrow 3) \alpha-\mathrm{L}-\mathrm{Rh}$ ap determinant is found in serotypes $6 \mathrm{~A}$ and $6 \mathrm{~B}$ and also in serotype 19A (Table 1). The same structure is also present in 6C PS as well (unpublished data). In contrast, 19F PS lacks this determinant and has an $\alpha$-D-Glcp $(1 \rightarrow 2) \alpha$-L-Rhap determinant instead. Also, serotype 2 PS has a $\beta$-D-Glcp $(1 \rightarrow 3) \alpha-L-R h a p$ determinant. Consequently, we used conventional ELISA with PS-coated ELISA plates to investigate the ability of Dob1 to bind to serotype $6 \mathrm{~A}, 6 \mathrm{~B}, 6 \mathrm{C}$, and 19A PS, as well as to serotype 2 and 19F PSs (Fig. 2A). The ELISA study clearly showed that Dob1 binds the pneumococcal PS of serotype 19A better than it binds the PSs of 6A, 6B, and 6C and that Dob1 did not bind to the PSs of serotypes 2, 14, or 19F. Thus, Dob1 selectively binds to the $6 \mathrm{~A}, 6 \mathrm{~B}, 6 \mathrm{C}$, and $19 \mathrm{~A}$ pneumococcal capsular PSs without binding to any other capsular PSs.

To test whether Dob1 binds to the pneumococcal capsular PS of the 19A serotype in solution, we evaluated its ability to bind to immobilized 6B PS in the presence of 19A PS in solution. As shown in Fig. 2B, 6B or 19A PS in solution could completely inhibit Dob1's ability to bind to immobilized 6B PS (Fig. 2B). Interestingly, 50\% of Dob1's binding ability could be inhibited with about $0.07 \mu \mathrm{g}$ of serotype $6 \mathrm{~B} \mathrm{PS} / \mathrm{ml}$, but the same binding inhibition could be achieved with only $0.007 \mu \mathrm{g}$ of serotype 19A PS/ml. 19F PS inhibited less than $10 \%$ of Dob1's binding ability even with $20 \mu \mathrm{g}$ of PS/ml. This is consistent with the facts that Dob1 can bind undenatured 19A PS in solution and that it actually binds to 19A PS better than to the three PSs of serogroup 6.

This surprising cross-reaction can be simply explained if the Dob1 hybridoma produces two different monoclonal antibody proteins: one clone acting as anti-19A and another clone acting as anti-6B. To exclude this technical possibility, we investigated the isoelectric points of Dob1 antibodies binding to $19 \mathrm{~A}$ and 6B PSs. As seen in Fig. 3, the IEF study showed that Dob1 has an antibody with the isoelectric point of 7.2 that binds to both type $6 \mathrm{~B}$ and 19A PS without binding to the PS of serotype 19F. Thus, Dob1 hybridoma produces
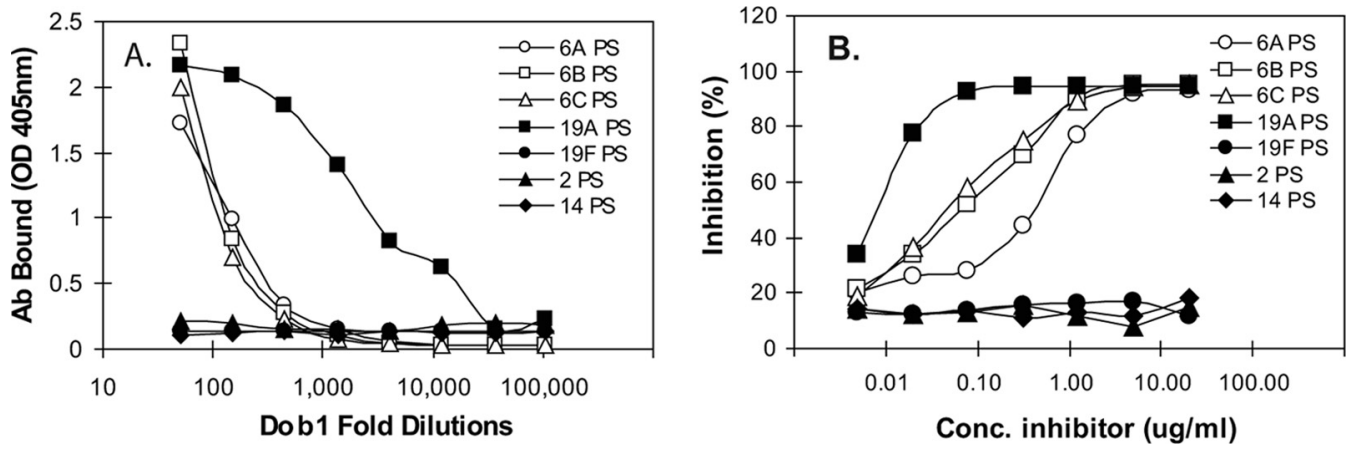

FIG. 2. Binding of Dob1 to seven different pneumococcal PSs immobilized to ELISA plates (A) and binding of Dob1 to serotype 6B PS immobilized to ELISA plates in the presence of various concentrations of seven different pneumococcal PSs in solution (B). The pneumococcal PSs are from serotypes $2(\boldsymbol{\Delta}), 6 \mathrm{~A}(\bigcirc), 6 \mathrm{~B}(\square), 6 \mathrm{C}(\triangle), 14(\bullet), 19 \mathrm{~A}(\boldsymbol{\square})$, and 19F $(\bullet)$. 


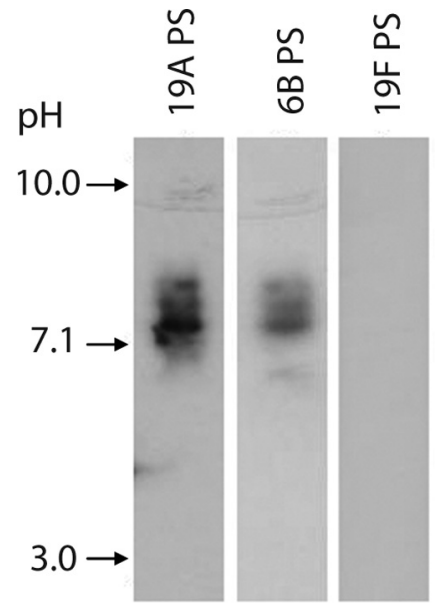

FIG. 3. IEF pattern of the Dob1 monoclonal antibody. Dob1 was separated by IEF; transferred to PVDF membranes coated with pneumococcal PSs serotype 19A (lane 1), 6B (lane 2), or 19F (lane 3); and visualized with enzyme-conjugated goat antibody to human IgG. The $\mathrm{pH}$ of the focusing gel is indicated on the left.

one monoclonal antibody that binds to $6 \mathrm{~B}$ PS, as well as to 19A PS.

Dob1 can opsonize and kill pneumococci. To determine whether an antibody with this unusual binding pattern is protective, we determined whether Dob1 can opsonize and kill pneumococci in vitro using pneumococci expressing seven different serotypes. Consistent with its binding preference, Dob1 opsonized 19A the best (killed $50 \%$ at 1:300 dilution) but also readily killed pneumococci expressing serotypes $6 \mathrm{~A}, 6 \mathrm{~B}$, and 6C (50\% killing at $1: 30$ to $1: 120$ ) (Fig. 4). In contrast, Dob1 killed less than $10 \%$ of pneumococci expressing three other serotypes (serotypes 4, 14, and 19F) even before any dilution. Thus, antibodies to this well-defined epitope can be protective against serotype 19A and serogroup 6 pneumococci.

Dob1-like antibodies are found in serum samples. Although Dob1 has an unusual cross-reaction between serotypes 19A

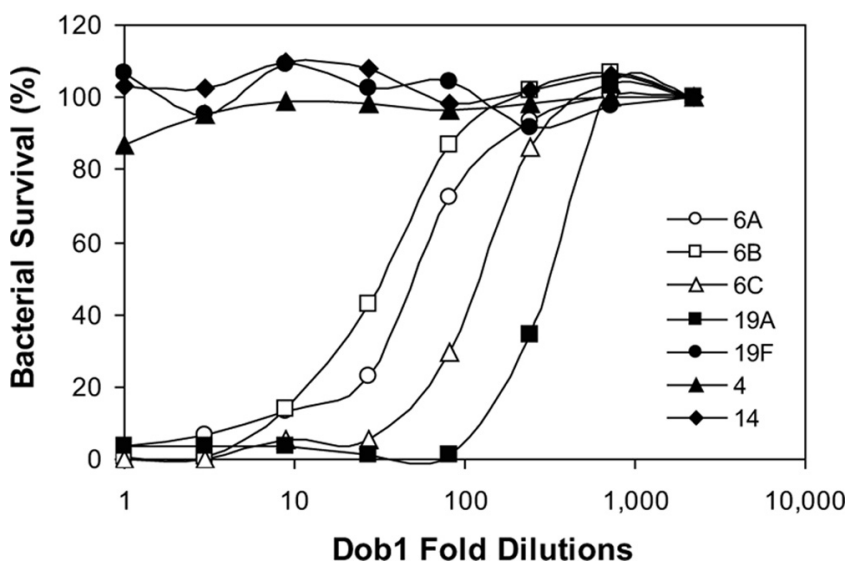

FIG. 4. Opsonophagocytic killing of pneumococci by a Dob1 hybridoma culture supernatant. The $y$ axis shows the percentage of surviving pneumococci, and the $x$ axis shows the dilution of Dob1 supernatant. The target bacteria used in the assay include pneumococci expressing serotypes $4(\boldsymbol{\Delta}), 6 \mathrm{~A}(\bigcirc), 6 \mathrm{~B}(\square), 6 \mathrm{C}(\triangle), 14(\bullet), 19 \mathrm{~A}(\mathbf{\square})$, and $19 \mathrm{~F}(\mathbf{\bullet})$.
TABLE 2. Number of serum samples with anti-6B antibodies that could be inhibited by 19A PS or 19F PS ${ }^{a}$

\begin{tabular}{|c|c|c|c|c|c|c|}
\hline \multirow{3}{*}{$\begin{array}{c}\% \\
\text { Inhibition } \\
\text { by } 19 \mathrm{~F} \\
\text { PS }\end{array}$} & \multicolumn{6}{|c|}{ No. of serum samples showing inhibition by 19A PS } \\
\hline & \multicolumn{3}{|c|}{ PCV9 $(n=116)$} & \multicolumn{3}{|c|}{ PPV23 $(n=59)$} \\
\hline & $\begin{array}{l}<30 \% \\
\text { inhibition }\end{array}$ & $\begin{array}{l}30-50 \% \\
\text { inhibition }\end{array}$ & $\begin{array}{l}>50 \% \\
\text { inhibition }\end{array}$ & $\begin{array}{c}<30 \% \\
\text { inhibition }\end{array}$ & $\begin{array}{l}30-50 \% \\
\text { inhibition }\end{array}$ & $\begin{array}{l}>50 \% \\
\text { inhibition }\end{array}$ \\
\hline$<30$ & 100 & 8 & 2 & 53 & 2 & 0 \\
\hline $30-50$ & 5 & 1 & 0 & 4 & 0 & 0 \\
\hline$>50$ & 0 & 0 & 0 & 0 & 0 & 0 \\
\hline Total & 105 & 9 & 2 & 57 & 2 & 0 \\
\hline
\end{tabular}

${ }^{a}$ Immune sera were obtained from volunteers vaccinated with either PCV9 or PPV23. PCV9 contains only 19F PS, but PPV23 contains both 19A and 19F PS. The percent inhibition indicates the relative reduction of serum antibodies binding to $6 \mathrm{~B}$ PS on the ELISA plates in the presence of either 19A or 19F PS in solution $(2 \mu \mathrm{g} / \mathrm{ml})$.

and 6 , since it is a monoclonal antibody, it is unclear whether natural antibodies in immune sera would exhibit this unusual cross-reaction pattern. To study the presence of Dob1-like antibodies in human immune sera, we tested sera from 175 vaccinees for this unusual cross-reaction property by investigating the ability of $19 \mathrm{~A}$ or $19 \mathrm{~F}$ PS in solution to inhibit anti-6B antibodies binding to 6B-coated ELISA plates. Of 175 serum samples screened (Table 2$)$, the great majority $(n=153)$ were inhibited by $19 \mathrm{~F}$ or $19 \mathrm{~A}$ PS for less than $30 \%$ of anti-6B antibodies, which suggested that anti-6B antibodies in most individuals are serogroups 6 specific. In 12 cases, the 19A PS inhibited more than $30 \%$, whereas the 19F PS inhibited less than $30 \%$. In 2 of these 12 individuals, the 19A PS could neutralize almost all anti-6B antibodies (Table 2) just as it did Dob1. In these two individuals, 19A PS (at $2 \mu \mathrm{g} / \mathrm{ml}$ ) could completely inhibit their ability to opsonize $6 \mathrm{~B}$ target bacteria as 6B PS does (data not shown). Thus, antibodies reacting with both 19A and 6B PSs are present in normal immune sera. Interestingly, 10 of the 12 persons were immunized with PCV9, including the two individuals showing complete cross-reaction. It is possible that PCV9 is more inclined to elicit Dob1-like antibodies than PPV23.

\section{DISCUSSION}

Dob1 has been known to us for years as a human monoclonal antibody that could bind to and opsonize pneumococci of serogroup 6 (30). A search for its epitope revealed it to be $\alpha$-D-Glcp $(1 \rightarrow 3) \alpha$-L-Rhap, which is present in the serogroup 6 PSs, as well as in serotype 19A PS (14). Consistent with this finding, Dob1 bound to serotype 19A PS and opsonized pneumococci expressing serotype 19A for phagocytes. Dob1 binding was very specific, since Dob1 neither bound to nor opsonized serotypes 2 and 19F, which contain $\beta$-D-Glcp $(1 \rightarrow 3) \alpha$-L-Rhap or $\alpha$-D-Glc $p(1 \rightarrow 2) \alpha$-L-Rhap determinants, respectively. More remarkably, ca. $7 \%$ of the immune sera (12 of 175 sera) of volunteers vaccinated with PPV23 or PCV9 had detectable amounts of Dob1-like antibodies, i.e., reacted with 6B and 19A PSs but not with 19F PS. Thus, humans often produce antibodies to the $\alpha$-D-Glcp $(1 \rightarrow 3) \alpha$-L-Rha $p$ epitope, and these antibodies can cross-protect against four commonly found pneumococcal serotypes: 6A, 6B, 6C, and 19A.

The interserogroup cross-reaction observed with Dob1 is 
different from the broad cross-reactions observed with Baxendale's human IgM monoclonal antibodies to pneumococcal PS (2). These IgM hybridomas bound not only PSs from several different serogroups of pneumococci but also various endogenous antigens (2). Furthermore, their protective capacities were marginal: the most protective monoclonal antibodies could prolong the average survival of mice by 12 to $24 \mathrm{~h}$ in a sepsis model (2). These observations suggested that the $\operatorname{IgM}$ hybridomas might be natural antibodies reacting with pneumococcal PS. In contrast, Dob1 is IgG2 (30) and highly efficient at opsonizing pneumococci in vitro, providing unambiguous protection from pneumococcal infections in vivo (26). Furthermore, Dob1 shows a very specific cross-reaction pattern. For instance, Dob1 does not bind serotype 2 PS, which has a $\beta$-D-Glcp $(1 \rightarrow 3) \alpha$-L-Rha $p$ determinant, but it does bind to pneumococcal PSs with a $\alpha$-D-Glc $p(1 \rightarrow 3) \alpha$-L-Rhap determinant.

Interserogroup cross-reactions have previously been reported using antisera from animals. For instance, cross-reactions between serotypes 10A and 39 and between serotype 33D and serogroup 6 (8) are well known. However, the cross-reaction between serogroup 6 and serotype 19A has never been reported even though the serological properties of the $19 \mathrm{~A}$ serotype were extensively investigated $(6,7,15)$. Also, no interserogroup cross-reactions were reported with human sera. Most importantly, our study is, to our knowledge, the first identification of the chemical structure involved in the interserogroup cross-reaction.

Since the introduction of PCV7, the incidence of pneumococcal diseases caused by serotype 19A has become very high (18\% of all invasive pneumococcal diseases) in the USA (17), as well as in other countries $(16,29)$. Also, pneumococcal diseases caused by serogroup 6 are still common $(9,18,21)$ despite PCV7 usage, largely because of the increased prevalence of serotype 6C. So, the Dob1 epitope would be a valuable vaccine candidate since it may potentially replace three different PS-protein conjugates (6A, 6B, and 19A conjugates) in the 13 -valent vaccine. Dob1 appears to bind to the $\alpha$-DGlc $p(1 \rightarrow 3) \alpha-\mathrm{L}-\mathrm{Rha} p$ determinant weakly since Dob1 does not bind to a single epitope, but only to multimeric epitopes. Thus, unmodified $\alpha$-D-Glcp $(1 \rightarrow 3) \alpha$-L-Rhap may not elicit antibodies to serogroup 6 and serotype 19A, but its structural variants with higher affinity to Dob1 could. The presence of the Dob1 monoclonal antibody would significantly simplify producing a high-affinity variant(s) of $\alpha$-D-Glcp $(1 \rightarrow 3) \alpha-\mathrm{L}-\mathrm{Rhap}$

The immunogenic Dob1 epitope may be useful in supplementing PCV7 since PCV7 is ineffective against 19A and 6C, and antibodies to the Dob1 epitope appear to be opsonic. Also, the Dob1 epitope should be potentially useful in supplementing a recently approved 10 -valent conjugate vaccine, which does not contain 6A or 19A PS (23). There are several simple carbohydrates that have already been shown to elicit antibodies to several commonly found serotypes such as serotypes 3 (3), 14 (27), 23F (1), and 19F (12). Synthesized carbohydrate was recently used to produce a practically useful conjugate vaccine against hemophilus (32). Therefore, the Dob1 epitope may be combined with these simple carbohydrates to construct a pneumococcal vaccine effective against a large percentage of pneumococcal infections.

\section{ACKNOWLEDGMENTS}

The study was supported by NIH grant R01-AI-69695 awarded to M.H.N. and NSF-CAREER award CHE-0547566 awarded to A.V.D.

\section{REFERENCES}

1. Alonso de Velasco, E., A. F. Verheul, A. M. van Steijn, H. A. Dekker, R. G. Feldman, I. M. Fernandez, J. P. Kamerling, J. F. Vliegenthart, J. Verhoef, and H. Snippe. 1994. Epitope specificity of rabbit immunoglobulin G (IgG) elicited by pneumococcal type $23 \mathrm{~F}$ synthetic oligosaccharide- and native polysaccharide-protein conjugate vaccines: comparison with human antipolysaccharide $23 \mathrm{~F}$ IgG. Infect. Immun. 62:799-808.

2. Baxendale, H. E., M. Johnson, R. C. Stephens, J. Yuste, N. Klein, J. S. Brown, and D. Goldblatt. 2008. Natural human antibodies to pneumococcus have distinctive molecular characteristics and protect against pneumococcal disease. Clin. Exp. Immunol. 151:51-60.

3. Benaissa-Trouw, B., D. J. Lefeber, J. P. Kamerling, J. F. Vliegenthart, K. Kraaijeveld, and H. Snippe. 2001. Synthetic polysaccharide type 3-related di-, tri-, and tetrasaccharide-CRM(197) conjugates induce protection against Streptococcus pneumoniae type 3 in mice. Infect. Immun. 69:4698-4701.

4. Burton, R. L., and M. H. Nahm. 2006. Development and validation of a fourfold multiplexed opsonization assay (MOPA4) for pneumococcal antibodies. Clin. Vaccine Immunol. 13:1004-1009.

5. Fedson, D. S., and D. M. Musher. 1994. Pneumococcal vaccine, p. 517-564. In S. A. Plotkin and E. A. Mortimer (ed.), Vaccines, 2nd ed. The W. B. Saunders Co., Philadelphia, PA.

6. Heidelberger, M., and P. A. Rebers. 1960. Immunochemistry of the pneumococcal types II, V, and VI: the relation of type VI to type II and other correlations between chemical constitution and precipitation in antisera to type VI. J. Bacteriol. 80:145-153.

7. Heidelberger, M., and J. M. Tyler. 1964. Cross-reactions of pneumococcal types. J. Exp. Med. 120:711-719.

8. Henrichsen, J. 1995. Six newly recognized types of Streptococcus pneumoniae. J. Clin. Microbiol. 33:2759-2762.

9. Hicks, L. A., L. H. Harrison, B. Flannery, J. L. Hadler, W. Schaffner, A. S. Craig, D. Jackson, A. Thomas, B. Beall, R. Lynfield, A. Reingold, M. M. Farley, and C. G. Whitney. 2007. Incidence of pneumococcal disease due to non-pneumococcal conjugate vaccine (PCV7) serotypes in the United States during the era of widespread PCV7 vaccination, 1998-2004. J. Infect. Dis. 196:1346-1354.

10. Insel, R. A., A. Kittelberger, and P. Anderson. 1985. Isoelectric focusing of human antibody to the Haemophilus influenzae b capsular polysaccharide: restricted and identical spectrotypes in adults. J. Immunol. 135:2810-2816.

11. Jansen, W. T., S. Hogenboom, M. J. Thijssen, J. P. Kamerling, J. F. Vliegenthart, J. Verhoef, H. Snippe, and A. F. Verheul. 2001. Synthetic 6B di-, tri-, and tetrasaccharide-protein conjugates contain pneumococcal type $6 \mathrm{~A}$ and $6 \mathrm{~B}$ common and 6B-specific epitopes that elicit protective antibodies in mice. Infect. Immun. 69:787-793.

12. Jansen, W. T., and H. Snippe. 2004. Short-chain oligosaccharide protein conjugates as experimental pneumococcal vaccines. Indian J. Med. Res. 119(Suppl.):7-12.

13. Jansen, W. T., A. F. Verheul, G. H. Veeneman, J. H. van Boom, and H. Snippe. 2001. Revised interpretation of the immunological results obtained with pneumococcal polysaccharide $17 \mathrm{~F}$ derived synthetic di-, tri-, and tetrasaccharide conjugates in mice and rabbits. Vaccine 20:19-21.

14. Kamerling, J. P. 2000. Pneumococcal polysaccharides: a chemical view, p. 81-114. In A. Tomasz (ed.), Streptococcus pneumoniae molecular biology and mechanisms of disease. Mary Ann Liebert, Inc., New Rochelle, NY.

15. Kauffmann, F., E. Morch, and K. Schmith. 1940. On the serology of the pneumococcus group. J. Immunol. 39:397-426.

16. Mahjoub-Messai, F., C. Doit, J. L. Koeck, T. Billard, B. Evrard, P. Bidet, C. Hubans, J. Raymond, C. Levy, R. Cohen, and E. Bingen. 2009. Population snapshot of Streptococcus pneumoniae serotype 19A isolates before and after introduction of seven-valent pneumococcal vaccination for French children. J. Clin. Microbiol. 47:837-840

17. Moore, M. R., R. E. Gertz, Jr., R. L. Woodbury, G. A. Barkocy-Gallagher, W. Schaffner, C. Lexau, K. Gershman, A. Reingold, M. Farley, L. H. Harrison, J. L. Hadler, N. M. Bennett, A. R. Thomas, L. McGee, T. Pilishvili, A. B. Brueggemann, C. G. Whitney, J. H. Jorgensen, and B. Beall. 2008. Population snapshot of emergent Streptococcus pneumoniae serotype 19A in the United States, 2005. J. Infect. Dis. 197:1016-1027.

18. Nahm, M. H., J. Lin, J. A. Finkelstein, and S. I. Pelton. 2009. Increase in the prevalence of the newly discovered pneumococcal serotype $6 \mathrm{C}$ in the nasopharynx after introduction of pneumococcal conjugate vaccine. J. Infect. Dis. 199:320-325.

19. Parameswar, A. R., S. J. Hasty, and A. V. Demchenko. 2008. Synthesis of spacer-containing analogs of serogroup 6 pneumococcal oligosaccharides. Carbohydr. Res. 343:1707-1717.

20. Parameswar, A. R., P. Pornsuriyasak, N. A. Lubanowski, and A. V. Demchenko. 2007. Efficient stereoselective synthesis of oligosaccharides of Streptococcus pneumoniae serotypes $6 \mathrm{~A}$ and $6 \mathrm{~B}$ containing multiple 1,2-cis glycosidic linkages. Tetrahedron 63:10083-10091. 
21. Park, I. H., M. R. Moore, J. J. Treanor, S. I. Pelton, T. Pilishvili, B. Beal, M. A. Shelly, B. E. Mahon, and M. H. Nahm. 2008. Differential effects of pneumococcal vaccines against serotypes 6A and 6C. J. Infect. Dis. 198: 1818-1822.

22. Park, I. H., D. G. Pritchard, R. Cartee, A. Brandao, M. C. Brandileone, and M. H. Nahm. 2007. Discovery of a new capsular serotype (6C) within serogroup 6 of Streptococcus pneumoniae. J. Clin. Microbiol. 45:1225-1233.

23. Prymula, R., P. Peeters, V. Chrobok, P. Kriz, E. Novakova, E. Kaliskova, I. Kohl, P. Lommel, J. Poolman, J. P. Prieels, and L. Schuerman. 2006. Pneumococcal capsular polysaccharides conjugated to protein $\mathrm{D}$ for prevention of acute otitis media caused by both Streptococcus pneumoniae and non-typable Haemophilus influenzae: a randomised double-blind efficacy study. Lancet 367:740-748.

24. Rennels, M. B., K. M. Edwards, H. L. Keyserling, K. S. Reisinger, D. A Hogerman, D. V. Madore, I. Chang, P. R. Paradiso, F. J. Malinoski, and A. Kimura. 1998. Safety and immunogenicity of heptavalent pneumococcal vaccine conjugated to CRM197 in United States infants. Pediatrics 101:604611.

25. Robbins, J. B., R. Austrian, C. J. Lee, S. C. Rastogi, G. Schiffman, J. Henrichsen, P. H. Makela, C. V. Broome, R. R. Facklam, R. H. Tiesjema, and J. C. Parke, Jr. 1983. Considerations for formulating the second-generation pneumococcal capsular polysaccharide vaccine with emphasis on the crossreactive types within groups. J. Infect. Dis. 148:1136-1159.

26. Saeland, E., G. Vidarsson, J. H. Leusen, E. Van Garderen, M. H. Nahm, H. Vile-Weekhout, V. Walraven, A. M. Stemerding, J. S. Verbeek, G. T. Rijkers, W. Kuis, E. A. Sanders, and J. G. Van De Winkel. 2003. Central role of complement in passive protection by human IgG1 and IgG2 anti-pneumococcal antibodies in mice. J. Immunol. 170:6158-6164.

27. Safari, D., H. A. Dekker, J. A. Joosten, D. Michalik, A. C. de Souza, R. Adamo, M. Lahmann, A. Sundgren, S. Oscarson, J. P. Kamerling, and H. Snippe. 2008. Identification of the smallest structure capable of evoking opsonophagocytic antibodies against Streptococcus pneumoniae type 14. Infect. Immun. 76:4615-4623.

28. Scott, M. G., D. L. Crimmins, D. W. McCourt, I. Zocher, R. Thiebe, H. G. Zachau, and M. H. Nahm. 1989. Clonal characterization of the human IgG antibody repertoire to Haemophilus influenzae type b polysaccharide. III. A single VKII gene and one of several JK genes are joined by an invariant arginine to form the most common L chain V region. J. Immunol. 143:4110_ 4116.

29. Song, J. H., J. Y. Baek, H. S. Cheong, D. R. Chung, K. R. Peck, and H. L. Ko. 2009. Changes of serotype and genotype in Streptococcus pneumoniae isolates from a Korean hospital in 2007. Diagn. Microbiol. Infect. Dis. 63:271278.

30. Sun, Y., M. K. Park, J. Kim, B. Diamond, A. Solomon, and M. H. Nahm. 1999. Repertoire of human antibodies against the polysaccharide capsule of Streptococcus pneumoniae serotype 6B. Infect. Immun. 67:1172-1179.

31. Vakevainen, M., C. Eklund, J. Eskola, and H. Kayhty. 2001. Cross-reactivity of antibodies to type 6B and 6A polysaccharides of Streptococcus pneumoniae, evoked by pneumococcal conjugate vaccines, in infants. J. Infect. Dis. 184:789-793.

32. Verez-Bencomo, V., V. Fernandez-Santana, E. Hardy, M. E. Toledo, M. C. Rodriguez, L. Heynngnezz, A. Rodriguez, A. Baly, L. Herrera, M. Izquierdo, A. Villar, Y. Valdes, K. Cosme, M. L. Deler, M. Montane, E. Garcia, A. Ramos, A. Aguilar, E. Medina, G. Torano, I. Sosa, I. Hernandez, R. Martinez, A. Muzachio, A. Carmenates, L. Costa, F. Cardoso, C. Campa, M. Diaz, and R. Roy. 2004. A synthetic conjugate polysaccharide vaccine against Haemophilus influenzae type b. Science 305:522-525.

33. Whitney, C. G., M. M. Farley, J. Hadler, L. H. Harrison, N. M. Bennett, R. Lynfield, A. Reingold, P. R. Cieslak, T. Pilishvili, D. Jackson, R. R. Facklam, J. H. Jorgensen, and A. Schuchat. 2003. Decline in invasive pneumococcal disease after the introduction of protein-polysaccharide conjugate vaccine. N. Engl. J. Med. 348:1737-1746.

Editor: A. Camilli 